\title{
Research on the Integration of Modern Architectural Design with Ancient Architectural Design
}

\author{
Panyi Mao \\ Zhejiang Greentown Liuhe Architectural Design Co., Ltd, Zhejiang, Hangzhou, 310012
}

Keywords: Modern Architectural, Ancient Architectural, Integration Design

\begin{abstract}
Architecture plays an indispensable role in the progress of human society at all times. Architecture is the product of culture, representing a monument of human history and culture. Ancient Chinese architecture is a uniquely attractive piece of art. With its distinctive appearance, distinctive colors, and beautiful shapes, it is loved by countless people all over the world. Although the domestic architectural design education is not an early start, it has formed a diversified and open disciplinary system.
\end{abstract}

\section{Introduction}

In the development of the construction industry, pay great attention to the diversification of architectural design. The organic integration of ancient architectural concepts and modern architectural design can provide inspiration for the innovative development of architectural design. This article mainly elaborates the concept of ancient architecture and value, and then discusses the inheritance and development of ancient architecture concept in modern architectural design in detail. The cultural concept of ancient architecture is rich in content, such as the righteousness concept of Confucianism has a more abundant manifestation. The ancient architecture has a north-south central axis in the plane layout, so that the entire plane can be symmetrically arranged, which can be seen in ancient architecture. According to the doctrine of the doctrine, one can understand that the Doctrine of the Mean places more emphasis on the coexistence of all things and does not need to go extreme. Therefore, it is necessary to accommodate everything with the broadest mind. It is known as the Garden of Vanguards, is an inclusive product. In the concept of ancient architecture, the golden mean is a more important theoretical basis. In addition, the ritual thought in the ancient architectural concept is also the more common theoretical basis in the ancient architecture. Then there is the combination of Confucianism and Taoism as well as the ideology of Confucianism, Taoism and Confucianism, which can be seen in ancient architecture [1].

There are many forms of design of ancient buildings in our country, including the aesthetic and values of the time in the design. In addition, many other ancient buildings contain philosophical thoughts in the design. Adding these design concepts to modern architectural design can effectively improve the aesthetics of modern architectural design. The design of ancient architecture is based on wood structure, and the wood structure is gable, roof, girders, room, base and other building elements to promote soft link mainly with good toughness. In ancient architecture, the wall is not load-bearing, the wall can be used as a curtain wall can also be open walls, forming a continuous flow of space. Most of the ancient construction is based on a square "room" surrounded by 4 wooden posts, and the number and size of "interiors" affect the size of ancient buildings. In ancient China, odd numbers were used as auspicious numbers [2]. Therefore, the number of "interiors" in ancient buildings is singular, and the greater the number, the higher the status of masters. The ancient buildings in our country are symmetrically distributed courtyards from the center to the center along the building. Important buildings are built on the center line, showing centralized status; the secondary buildings are built on both sides of the center line, and the two sides are symmetrically built. In addition, in ancient architecture, there are many changes in the courtyard between the real and the actual, which emphasizes the architectural hierarchy. The decorative elements in ancient buildings are mainly rafters, brooms, brackets, etc., which make use of the carving on these components to exert their decorative functions. In addition, in the windows and 
doors, plaques, etc. also used art, sculpture and other technologies, to these decorative components increased a lot of color, reflecting the ancient Chinese cultural heritage.

\section{Ancient Architectural Features of Modern Architectural Design Education Impact Way}

Although modern architecture design education evolved from the architectural design education system in the early days, it can not fully copy their educational model to some extent. Therefore, it is necessary to show the characteristics of China in education. It can be said that the traditional ancient architecture is the treasure of human history, contrasting the modern architectural design, the ancient architecture contains the traditional culture, which contrasts strongly with the modern architectural design [3]. Therefore, reflecting on the lack of ancient culture in modern architectural design education, China's modern architectural design education continually determines the direction of self-development, resulting in a great impelling effect, driving the rapid development of educational concepts and values, and realizing the transformation of the teaching mode Exploration, inheritance and cultural transmission of education. In the decades of reform and opening up, the level of modern architectural design education has greatly improved in our country. Educators and scholars have continuously communicated with other countries and have contacted a large number of advanced Western designs and education, Of the educational methods brought to our country is constantly improving the architectural design education system, a large number of outstanding architectural design talents have been trained. The huge differences between beliefs and society in different countries and ethnic groups make the design culture of different countries and nations all show their own unique features. China's modern architectural design education should learn from the footsteps of ancient architectural design, so that ideological integration. Any design is closely related to the history, society, culture and geography of the nation. If we neglect the characteristics of education construction and traditional culture even the blind copying and imitation, the development of Chinese modern architecture will inevitably lose the ability of self-sustaining. Learning from the ancient architecture is not a simple imitation, but to seize the ancient architectural elements, combined with the process of modern building technology innovation process, which is the impact of modern architectural design education is an important way. In the process of education, with the cultural connotation and education experience presented, the contents of modern architecture design education have been updated in three aspects: First, to build a modern Architectural Design Education Framework. Of course, nowadays society can not carry out sensory learning. However, this mode of imparting training that emphasizes comprehensive ability training integrates theory, aesthetic and culture in architecture design into a logical framework. During the education of different cultural subjects in all stages, Feel the impact of ancient architecture; Second, in the architectural design education into the culture of ancient buildings. People can not only acquire the culture or knowledge but not rely on simple teaching. They must rely on the cultivation of the quality, pass the ancient architectural culture in a subtle and subtle way, and make the modern architectural design education truly embody and educate. Thirdly, integrate the modern architectural design Cultural transmission in education. To understand and interpret the cultural history of a nation, we must realize the conscious integration in a harmonious and different cultural environment. On the basis of integration and balance, experience and observation of the spiritual atmosphere of ancient buildings can make the thinking and human feelings grow more [4].

In the modern architecture design education, personalized education customization, teaching and architectural design can be integrated into the social environment, in line with the needs of the times, will make the entire modern architectural design education greatly enhance the practical value. It is the key way to influence the modern architectural design education to make the characteristics of the ancient architectural culture unique as the basis of the integration between ancient and modern times in order to make the expression of architectural design education change dramatically. With the improvement of environmental awareness, people continue to return to the original and natural, many folk art allows designers to create a new naturalization effect, the return of ancient architectural features make modern architectural design education more comfortable, and tends to artistic aesthetic. Modern architectural design education has been more emphasis on practical 
teaching, conduct research on ancient buildings, allowing students to study ancient buildings on the spot, but also on the impact of architectural design education. Maintaining a rigorous educational base of practice in the teaching of architecture design runs through the aesthetics of ancient architectural design in the face of an increasingly powerful trend of new architectural design ideas, teaching arrangements, including the ancient characteristics of the process of modern innovation is essential. No matter what the strict requirements, can not change the important position of basic training. Many architects and educators believe that no matter how students innovate in future study and architectural design, the cultivation of aesthetic awareness is indispensable and even satisfies the basic conditions for innovation. In the Suzhou garden and the Summer Palace and other places to visit the comparison, can understand the private garden and royal garden features and differences, from which you can even find the relationship between architectural design and other traditional art. In the close contact with the real object, this profound sensory impression inevitably leads to interest in the study of ancient architecture. It has obvious benefits to modern architecture design learning and has a far-reaching impact.

\section{Modern Architectural Design and the Integration of Ancient Architectural Design}

A reflection of the integration of modern architectural design with ancient architectural design is the use of ancient building materials in modern architectural design. Building materials is the most important part of architectural design, both modern and ancient have an important role in the design of modern architecture. For example, most of the materials of ancient buildings are made of wood, which makes the building feel close to nature. Most of the modern building materials are materials such as reinforced concrete. However, in the design, the characteristics of ancient building wood can be used to make art for example, He Jingtang, the architect of our country, put forward the conception of "architectural aesthetics" and took advantage of this concept in the China Pavilion at the 2010 World Expo. The bottom of the China Pavilion is composed of Concrete and steel structure, showing a solid structure of the United States, while the top is used to measure the weight of 56 piled up, a good representation of the arches of the ancient architectural wooden buildings in the beauty. The design at the bottom merges with the design at the top, showing the harmonious development of our culture [5].

A reflection of the integration of modern architectural design and ancient architectural design is the transformation of the appearance of ancient buildings or the commercial renovation of ancient streets. This situation is mostly used in tourist attractions in a wide range of applications. For example: in the ancient city of Xiangxi in Hunan Diaojiaolou is mainly built of wood, and the wooden structure of the building is not suitable as a hotel, restaurant, in order to meet the needs of the ancient city of commercial tourism, the Diaojiao building from reinforced concrete to multi-layer Building to meet the needs of operating hotels, restaurants, in the heart of the ancient city of Phoenix built more than 700 hotels and hotels, there are more than 2,000 restaurants. In addition, on the basis of protecting the original appearance of ancient buildings in Fenghuang City and integrating the design concepts and characteristics of modern architecture into the overall planning of Fenghuang Street, it not only can preserve the ancient buildings in the ancient town, but also transform the local part of the ancient town into commercial To enable tourists to enjoy the ancient building on the basis of the modern service can also enjoy, thus promoting the ancient city of Phoenix tourism industry and economic development.

The fusion of modern architectural design and ancient architectural design is the idea of "Chinese inherent" architecture put forward in the Republic of China. The idea of "Chinese inherent" architecture refers to the design of buildings with western architectural design techniques to design buildings with ancient architectural styles in our country. China's Republic of China architectural design makes the design of architectural forms and styles tend to the ancient architecture of our country, and the use of building materials and technology is the same as the West, which is due to the Republic of China during the architects by the "Chinese-style" building The impact of Chinese and Western cultures on China's architectural design thinking. 


\section{Conclusions}

The concept of ancient architecture applied to the design of modern architecture for the development of inheritance, we must focus on reality, in accordance with the actual development of the situation to choose to apply the concept of ancient architecture as the design of the core, from many aspects of the use of elements, so there to help the effective integration of modern architecture and ancient architecture, to create a different architectural design style. Hope that through this theoretical study, the modern architectural design innovation and development play a catalytic role.

\section{References}

[1] Zhang Ling.Aesthetic Isomorphism of Classical Literature and Architectural Art under the Background of Traditional Chinese Culture [J]. Dongyue, 2015,36 (12): 62-67.

[2] Zhu Wenli. Cultural Expression of Traditional Building Decoration Materials in Modern Landscape Design [J]. Art Observation, 2015,20 (6): 127-128.

[3] Monina, Yang Jin, Zheng Min. Cultural Consciousness of Modern Architecture Education [J]. Chinese Culture Forum, 2015,107 (3): 127-131.

[4] Ren Jian. Modern Art Design and the Integration of Chinese Tea Ceremony [J]. Fujian Tea, 2016,38 (9): 229-230.

[5] Wang Hao. The Future Development of Antique Buildings [J]. Residential and Real Estate, 2016, (36): 272.

[6] Liu Shuang. Discussion on the Integration of Modern Architectural Design and Ancient Architectural Design [J]. Engineering Technology Research, 2016, (6): 245. 